\title{
Usefulness of acidity and temperature of the rumen and abomasum in diagnosing SARA in dairy cows after calving
}

\author{
R. Antanaitis ${ }^{1}$, V. Žilaitis ${ }^{1}$, V. Juozaitienè $\dot{2}^{2}$ R. Stoškus ${ }^{1}$ \\ ${ }^{1}$ Department of Non-Infectious Diseases \\ ${ }^{2}$ Department of Animal Breeding and Nutrition \\ Veterinary Academy, Lithuanian University of Health Sciences, Tilžès 18, Kaunas, Lithuania
}

\begin{abstract}
The aim of the research was to determine the relationship between the acidity and temperature of the contents of the reticulorumen and abomasum in the first 10 days after calving and to evaluate these factors as predictive traits for the diagnosis of subclinical acidosis.

The acidity and temperature of the contents of the reticulorumen and abomasum were measured using specific smaXtec boluses manufactured for animal care. According to the directions of the manufacturer, the boluses were inserted into the reticulorumen of the cows researched with the help of a specific tool. The boluses were inserted into the abomasa by way of surgery, laparotomy and abomasotomy through the right flank. The readings of 7 cows were taken on a total of 10 days, twice a day (at 9 a.m. and at 9 p.m.). In total, 140 measurements were taken.

The acidity of the reticulorumen is associated with the acidity of the abomasum. The acidity of the rumen increases, if the acidity of the reticulorumen increases also. A negative correlation was observed between the $\mathrm{pH}$ of the contents of the abomasum and this temperature. The increase in the acidity (decrease of $\mathrm{pH}$ ) of the contents of the reticulorumen increases its temperature and also increases the temperature of the contents of the abomasum. There is a positive statistically significant dependence between the reticulorumen content temperature and the rectal temperature.

Through measurement of the ruminoreticular temperature, it is possible to predict the health status of a cow's stomach in regard to acidosis.
\end{abstract}

Key words: reticulorumen, abomasum, $\mathrm{pH}$, temperature, acidosis

\section{Introduction}

Subacute ruminal acidosis (SARA) is likely to arise when an easily palatable, high-energy diet meets a ruminal environment that is not adapted to this type of diet. This condition can be seen in the digestive tracts of fresh dairy cows. In this case, an increase in short-chain fatty acids will occur. Eventually, this can result in a decrease in the ruminal $\mathrm{pH}$ to below 5.5 (Kleen et al. 2003). Higher levels of intake may also predispose the rumen to SARA, since the salivary buffer secretion may not adequately compensate for 
the additional acid production (Stone 2003). During SARA, rumen $\mathrm{pH}$ is depressed for several hours per day due to the accumulation of volatile fatty acids and insufficient rumen buffering (Plaiziera et al. 2008). Early signs of SARA are not usually evaluated through clinical observations. Rumen acidosis, mainly occurring as SARA, is characterized by an abnormally low reticulorumen $\mathrm{pH}$. SARA is a widely spread problem in high yielding dairy cows (Bramley et al. 2008). Because the $\mathrm{pH}$ of body fluids is buffered by bicarbonate, the $\mathrm{pH}$ of body fluids may or may not be depressed during acidosis. It is possible that the feed acidity also affects the acidity of the body fluids and the abomasum's. It has been observed that there is a genetic correlation between the rumen acids and their temperature (Gengler et al. 2010). The ruminal $\mathrm{pH}$ nadir had a negative relationship with the corresponding ruminal temperature $\left(\mathrm{R}^{2}=0.77\right)$. Therefore, the reticulorumen temperature may have the potential to predict ruminal $\mathrm{pH}$, and thus aid in the diagnosis of SARA (AlZahal et al. 2008). Reticuloruminal fluid analysis can aid in making a diagnosis of subacute ruminal acidosis during the first stage of the disease. Feed grain caused a rapid increase in the volatile fatty acid concentrations of ruminal and abomasal fluid (Svendsen et al. 1970). It is possible that subclinical acidosis involves the abomasum. The reticuloruminal $\mathrm{pH}$ in grazing cattle can be measured in rumen fluid, which is either collected via a stomach tube (Bramley et al. 2008), or by rumenocentesis (Nordlund and Garret 1994). The technique used to collect ruminal fluid affects the outcome of the measured pH values (Dirksen 1990). Strabel et al. (2007) found that samples taken via a stomach tube showed values that were $0.5 \mathrm{pH}$-units higher than those taken by rumenocentesis because the samples were contaminated by saliva. Rumenocentesis can also have negative effects on animal health. Recent techniques use indwelling $\mathrm{pH}$ probes placed in the rumen (Duffield et al. 2004) or in the reticulorumen (Gasteiner et al. 2009a). Continuous monitoring of the reticuloruminal $\mathrm{pH}$ is advantageous due to the possibility of diurnal recording (Duffield et al. 2004). Techniques for the continuous measurement of ruminal $\mathrm{pH}$ were used for a series of scientific investigations (Alzahal et al. 2008). In order to obtain the collected data, a memory chip either has to be removed via the rumen (Keunen et al. 2002), or the data is transmitted by cable to an external unit, which is fixed to the animal (Alzahal et al. 2008). Gasteiner et al. (2009b) described and evaluated a method for measuring reticuloruminal $\mathrm{pH}$ continuously, which uses a wireless data transmitting unit to allow long-term monitoring. Rumen cannulated cattle are not essential when using this technique, as the probes are given orally. Repeat- ed measurement of the reticuloruminal $\mathrm{pH}$ remains the only way to quantify the balance between acid production, acid removal, and the buffering capacity in the rumen (Westwood et al. 2003). The reticuloruminal $\mathrm{pH}$ was significantly influenced by the diet. It can be concluded that SARA might occur under practical conditions in dairy cows during a period of feed changeover and when pasture feeding is combined with the supplemental feeding of grain-based concentrates. The indwelling $\mathrm{pH}$ measuring device is a very helpful tool and can also be used for practical purposes (Gasteiner et al. 2012). In a previous study, Enemark et al. (2003) used devices which were initially developed for marine animals and observed a slightly positive electrode drift after ten days of continuous application in the reticulorumen of cows. In a study of Kaur et al. (2010), a predecessor generation of probes for intraruminal $\mathrm{pH}$, temperature and pressure measurement produced by the same manufacturer was evaluated utilizing fistulated sheep for ten day periods. The microbial dysbiosis occurring in the rumen during acidosis may trigger the release of potential harmful molecules which may impact on animal health. Indeed, due to an increase in the death and lysis of Gram-negative bacteria under low $\mathrm{pH}$, free lipopolysaccharide (LPS) concentration is increased in the rumen fluid and translocation of this endotoxin can occur across the rumen mucosa (Commun et al. 2009). Moreover, the low $\mathrm{pH}$ of rumen digesta may have a negative impact on rumen wall integrity. Repeated aggression by fermentation acids may cause papillar atrophy, diffuse areas of acute or chronic lesions, scars resulting from severe local rumenitis, perforations and mucormycosis, which are the origin of pain and discomfort, as well as erratic feed intake and the alteration of rumen function (Thompson et al. 2006). Low ruminal $\mathrm{pH}$ is often associated with the increased occurrence of bloat, which is characterized by an accumulation of gas in the rumen and reticulorumen (Wang et al. 2012).

The aim of this study was to determine the relationship between the acidity and temperature of the contents of the reticulorumen and abomasum in the first 10 days after calving, and to evaluate these factors as predictive traits for the diagnosis of subclinical acidosis.

\section{Materials and Methods}

The study was performed on 7 dairy cows: second lactation and fresh (up to 10 days after calving) Lithuanian Black and White cows. The herd consisted of 400 dairy cows in total. All the cows researched were kept in a uniform environment and received 
Table 1. Correlation between the parameters of the contents of the reticulorumen and abomasum.

\begin{tabular}{llcccc}
\hline & Characteristics & $\mathrm{RpH}$ & $\mathrm{Rt}$ & $\mathrm{AbpH}$ & $\mathrm{Abt}$ \\
\hline $\mathrm{RpH}$ & Pearson correlation & 1 & $-0.199^{*}$ & $0.250^{* *}$ & $-0.429^{* *}$ \\
& Sig. (2-tailed) & & 0.016 & 0.002 & 0.0001 \\
\hline $\mathrm{Rt}$ & Pearson correlation & $-0.199^{*}$ & 1 & $-0.456^{* *}$ & $0.509^{* *}$ \\
& Sig. (2-tailed) & 0.016 & & 0.0001 & 0.0001 \\
\hline $\mathrm{AbpH}$ & Pearson correlation & $0.250^{* *}$ & $-0.456^{* *}$ & 1 & -0.103 \\
& Sig. (2-tailed) & 0.002 & 0.0001 & 0.218 \\
\hline Abt & Pearson correlation & $-0.429^{* *}$ & $0.509^{* *}$ & -0.103 & 1 \\
& Sig. (2-tailed) & 0.0001 & 0.0001 & 0.218 & \\
\hline
\end{tabular}

$\mathrm{RpH}$ : reticuloruminal $\mathrm{pH}$; $\mathrm{Rt}$ : reticuloruminal temperature; $\mathrm{AbpH}$ : abomasal $\mathrm{pH}$; Abt: abomasal temperature

a uniform ration suitable for this stage of lactation. The average yield of the cows researched was $30( \pm 3)$ $\mathrm{kg} / \mathrm{d}$.

Before the study, the cows selected were examined according to a general clinical examination plan, and were completely healthy. Clinical signs of acidosis (diarrhoea, loss of appetite, and weak rumination (on average, 3 times/2 min) were not found. The average somatic cell concentration in the milk of the cows studied was about $250( \pm 32)$ thousand/ml, and the milk urea was $25( \pm 4) \mathrm{mg} / \%$.

The $\mathrm{pH}$ and temperature of the contents of their reticulorumens and abomasa were measured using specific smaXtec boluses manufactured for animal care. SmaXtec animal care technology ${ }^{\circledR}$ enables the continuous real-time display of data such as ruminal $\mathrm{pH}$ and temperature. According to the directions of the manufacturer, the boluses were inserted into the reticulorumens with the help of a specific tool. The boluses were inserted into the abomasa by way of surgery, laparotomy and abomasotomy through the right flank, and were fixed to the base of the abomasa 90 days prior to the survey. Preparation of the animal for surgery includes removal of the hair and cleansing of the skin around the surgical site. Laparotomy and abomasotomy are surgeries performed for treating many ruminal disorders in bovines. Anaesthetic techniques required for abomasotomy are para-vertebral nerve block by use of lignocaine hydrochloride. A long vertical skin incision starting about three to four centimeters below the transverse process of the lumbar vertebrae is made. The abdominal muscles and peritoneum are also incised corresponding to the skin incision. The abomasal incision (about 20-cm long) was made directly over the mass in the region of the greater curvature of the pyloric part of the abomasum. The abomasum incision is closed by a double row of continuous inverting sutures using a chromic catgut.

The data was measured with the help of specific antennas (smaXtec animal care technology ${ }^{\circledR}$ ). For monitoring the reticuloruminal $\mathrm{pH}$, an indwelling and wireless data transmitting system (smaXtec animal care GmbH, Graz, Austria) was used (Gasteiner et al. 2009a). The data collected was transmitted using the ISM-Band (433 MHz). The system was controlled by a microprocessor. The data ( $\mathrm{pH}$ and temperature) was collected by means of an analogue to digital converter $(\mathrm{A} / \mathrm{D}$ converter) and stored in an external memory chip. Due to its dimensions (length: $12 \mathrm{~cm}$; width: $3.5 \mathrm{~cm}$; weight: $210 \mathrm{~g}$ ), this indwelling system can be orally administered to an adult cow, and it is shock-proof and resistant to rumen fluid (D.L.G. 2010). Calibration of the $\mathrm{pH}$-probes was performed using $\mathrm{pH} 4$ and $\mathrm{pH} 7$ buffer solutions at the beginning of the experiment.

The rectal temperature was measured according to the clinical study plan requirements.

The readings of 7 cows were taken on a total of 10 days, twice a day (at 9 a.m. and at 9 p.m.). In total, 140 measurements were taken. All the data were obtained by smaXtec messenger ${ }^{\circledR}$ computer software.

Descriptive statistic of the sample (arithmetic mean \pm standard error) was calculated using the SPSS statistical package (SPSS for Windows 15.0, SPSS Inc., Chicago, IL, USA, 2006). Relationships between the traits were analysed using Pearson's coefficient and linear regression equation: $\mathrm{y}=\mathrm{bx}+\mathrm{a}$ (where $\mathrm{x}$ is the explanatory variable and $y$ is the dependent variable; the slope of the line is $b$, and a is the intercept, i.e., the value of $y$ when $x=0 . R^{2}$ was determined as a statistical measure of how close the data is to the fitted regression line). The data was considered reliable from a statistical point of view, where $\mathrm{p}<0.05$.

\section{Results}

A total of 140 measurements were made. The medium reticulorumen $\mathrm{pH}$ was $5.964( \pm 0.008)$, and the medium temperature was $38.981^{\circ} \mathrm{C}( \pm 0.040)$. The medium $\mathrm{pH}$ of the abomasal content was at 2.8378 (0.028), and the temperature was $38.908^{\circ} \mathrm{C}( \pm 0.011)$. 


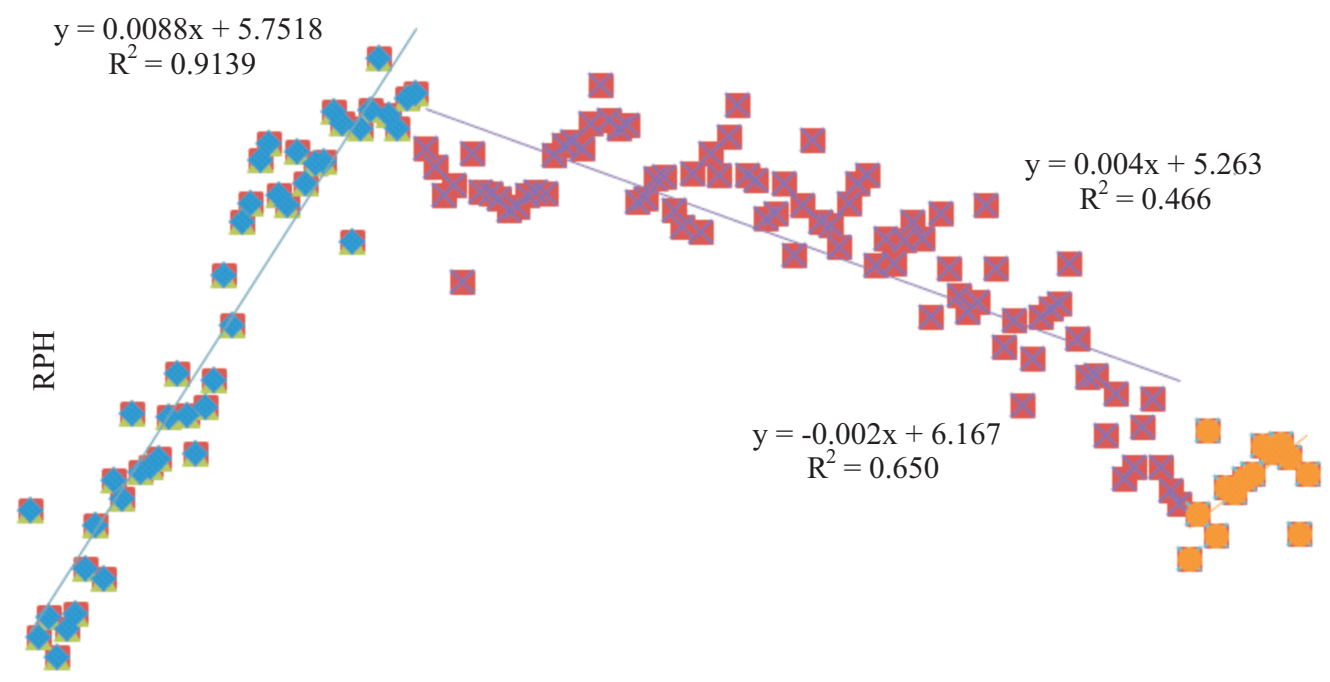

INTERVAL

Fig. 1. Analysis of the correlation between the $\mathrm{pH}$ of the contents of the reticulorumen and the interval. $\mathrm{RpH}$ : reticulorumen $\mathrm{pH}$.

The correlation between the parameters of the contents of the reticulorumens and abomasum observed during the study are shown in Table 1.

The following correlations were identified: a negative statistically significant correlation $(r=-0.199$, $\mathrm{p}<0.05$ ) between the $\mathrm{pH}$ and the temperature of the contents of the reticulorumen. The decrease in the $\mathrm{pH}$ of the contents of the reticulorumen increases its temperature. A positive statistically significant correlation $(\mathrm{r}=0.250, \mathrm{p}<0.01)$ was found between the $\mathrm{pH}$ of the contents of the reticulorumen and abomasum. The decrease of the $\mathrm{pH}$ of the contents of the reticulorumen decreases the $\mathrm{pH}$ of the contents of the abomasum. A negative statistically significant correlation $(r=0 .-429, p<0.001)$ was identified between the $\mathrm{pH}$ of the contents of the reticulorumen and the temperature of the contents of the abomasum. The decrease of the $\mathrm{pH}$ of the contents of the reticulorumen increases the temperature of the contents of the abomasum. A negative statistically significant correlation $(\mathrm{r}=-0.456, \mathrm{p}<0.001)$ was demonstrated between the temperature of the contents of the reticulorumen and the $\mathrm{pH}$ of the contents of the abomasum. The decrease of the $\mathrm{pH}$ of the contents of the abomasum increases the temperature of the contents of the reticulorumen. A positive statistically significant correlation $(\mathrm{r}=0.509, \mathrm{p}<0.001)$ was found between the temperature of the contents of the reticulorumen and the abomasum. The increase of the temperature of the contents of the reticulorumen increases the temperature of the contents of the abomasum. A negative correlation $(r=-0.103, p>0.05)$ was observed between the temperature and the $\mathrm{pH}$ of the contents of the abomasum. The decrease of the $\mathrm{pH}$ of the contents of the abomasum increases the temperature of the contents of the abomasum. However, this correlation was statistically insignificant. A positive statistically significant correlation was found between the reticulorumen content temperature and the rectal temperature. With an increase of reticulorumen content temperature, the rectal temperature also increases $(\mathrm{r}=0.257),(\mathrm{p}<0.0001)$.

The analysis shows a regular linear increase of $\mathrm{RpH}$ in the interval from 1 to $43(\mathrm{y}=0.0088 \mathrm{x}$ $+5.7518 ; \mathrm{R}=0.9138)$, a decrease in the interval from 44 to $126(\mathrm{y}=-0.002 \mathrm{x}+6.1676 ; \mathrm{R}=0.6501)$, and an increase in the interval from 127 to $140(\mathrm{y}=0.0044 \mathrm{x}$ + 5.2637; $\mathrm{R}=0.4664$ ) (Fig. 1).

\section{Discussion}

The results of our study confirm the information found in the literature. It showed a negative statistically significant correlation $(\mathrm{r}=-0.199, \mathrm{p}<0.05)$ between the temperature and $\mathrm{pH}$ of the contents of the reticulorumen. A close relationship between the rumen $\mathrm{pH}$ and temperature as, indicated by AlZahal et al. (2008), would be expected to be inverse and to especially arise during intensive postprandial fermentation, reflecting a decreasing rumen $\mathrm{pH}$, but an increasing rumen temperature. An inverse relationship of $\mathrm{r}=-0.39$ between the rumen $\mathrm{pH}$ obtained by manual determination in fluid withdrawn from the ventral rumen sac of sheep and the bolus temperature measured in vivo was found by Kaur et al. (2010). Duffield et al. (2004) observed varying but mainly weak relationships between the $\mathrm{pH}$ measurement via a device placed in the ventral sac of the rumen of cows and the manual $\mathrm{pH}$ determination in the second $200 \mathrm{ml}$ of 
rumen fluid obtained by a tube-like probe through a rumen cannula from different intraruminal sites. AlZahal et al. (2008) observed a correlation of $r=-0.46$ between the ventral rumen $\mathrm{pH}$ and temperature using an indwelling electrode measuring both parameters simultaneously in lactating dairy cows, although the direct proximity of both sensors may have contributed to the close relationship. The authors developed an equation for the prediction of rumen $\mathrm{pH}$ from rumen temperature and thus discussed the potential of rumen temperature as an indicator for the detection of SARA in cattle. AlZahal et al. (2008) reported a significant increase in rumen temperature due to feeding high amounts of grain in comparison to a mixed hay diet. The devices used for evaluation showed a moderate linear relationship and an agreement of $\mathrm{pH}$ measurement with the applied manual method, a fact that could be due to a lack of accuracy in the manual $\mathrm{pH}$ determination (Lohölter et al. 2013). The research showed a positive statistically significant correlation $(\mathrm{r}$ $=0.509, \mathrm{p}<0.001$ ) between the temperature of the contents of the reticulorumen and the abomasum. An association with general body temperature might be presumed in this case. A close correlation $(r=0.65)$ between the reticulorumen temperature measured via an indwelling probe and the rectal temperature of intact dairy cows was observed by Bewley et al. (2008) and based on a large number of paired samples, which were taken during several seasons. Burns et al. (2002) used the same technique in cows near the occurrence of oestrus and reported a relationship of $r=0.50$ between reticular and rectal temperature. However, a close correlation between rumen and rectal temperature $(r=0.92)$ was reported for rumen-fistulated lactating cows in a former study using a prototype rumen bolus (Sievers et al. 2004). Therefore, regular measurement of body temperature could be part of a routine systemic monitoring in cattle farms (Drillich et al. 2001).

The following conclusions can be drawn from the results. The increase of the temperature of the contents of the reticulorumen decreases its $\mathrm{pH}$ and the $\mathrm{pH}$ of the contents of the abomasum, and increases the temperature of the contents of the abomasum. The decrease of the $\mathrm{pH}$ of the contents of the reticulorumen increases the temperature of the contents of the abomasum. Through measurement of the ruminoreticular temperature, it is possible to predict the health status of a cow's stomach in regard to acidosis.

\section{References}

AlZahal O, Kebreab E, France J, Froetschel M, McBride BW (2008) Ruminal temperature may aid in the detection of subacute ruminal acidosis. J. Dairy Sci 91: 202-207.
Bewley JM, Einstein ME, Grott MW, Schutz MM (2008) Comparison of reticular and rectal core body temperatures in lactating dairy cows. J Dairy Sci 91: 4661-4672.

Bramley E, Lean IJ, Fulkerson WJ, Stevenson MA, Rabiee AR, Costa ND (2008) The definition of acidosis in dairy herds predominantly fed on pasture and concentrates. J Dairy Sci 91: 308-321.

Burns P, Wailes W, Baker P (2002) Changes in reticular and rectal temperature during the periestrous period in cows. J Anim Sci 80: 128-129.

Commun L, Alves de Olivera L (2009) L'acidose subclinique chez les ruminants. Consequences comportementales et indicateurs physiologiques peripheriques. J Nat GTV 1091-1100.

Deutsche Landwirtschafts-Gesellschaft (D.L.G.) (2010) Pansensaftbesandigkeit Eines Intraruminalen Messsystems 5973

Dirksen G (1990) Verdauungsapparat in die klinische Untersuchung des Rindes, 3: 288-400.

Drillich M, Beetz O, Pfutzner A, Sabin M, Sabin HJ, Kutzer P, Natterman H, Heuwieser W (2001) Evaluation of a systemic antibiotic treatment of toxic puerperal metritis in dairy cows. J Dairy Sci 84: 2010-2017.

Duffield T, Plaizier JC, Fairfield A (2004) Comparison of techniques for measurement of rumen $\mathrm{pH}$ in lactating dairy cows. J Dairy Sci 87: 59-66.

Enemark JM, Peters G, Jorgensen RJ (2003) Continuous monitoring of rumen $\mathrm{pH}$ a case study with cattle. J Vet Med A 50: 62-66.

Gasteiner J, Fallast M, Rosenkranz S, Hausler J, Schneider K, Guggenberger T. (2009b) Zum Einsatz einer intraruminalen $\mathrm{pH}$-Datenmesseinheit mit kabelloser Datenubertragung bei Rindern unter verschiedenen Futterungsbedingungen. Vet Med Austria 96: 188-194.

Gasteiner J, Fallast M, Rosenkranz S, Häusler J, Schneider $\mathrm{K}$, Guggenberger T (2009a). Measuring rumen $\mathrm{pH}$ and temperature by an indwelling and data transmitting unit and application under different feeding conditions. In: Proceedings of the Livestock Precision Farming pp 127-133.

Gasteiner J, Guggenberger T, Häusler J, Steinwidder A (2012) Continuous and long-term measurement of reticuloruminal $\mathrm{pH}$ in grazing dairy cows by an indwelling and wireless data transmitting unit. Vet Med Int. 2012: 1155.

Gengler WR, Martz FA, Johnson HD (2010) Effect of temperature on food and water intake and rumen fermentation. J Dairy Sci 53: 434-437.

Kaur R, Garcia SC, Horadagoda A, Fulkerson WJ (2010) Evaluation of rumen probe for continuous monitoring of rumen $\mathrm{pH}$, temperature and pressure. Anim Prod Sci 50: 98-104.

Keunen JE, Plaizier JC, Kyriazakis L (2002) Effects of a subacute ruminal acidosis model on the diet selection of dairy cows. J Dairy Sci 85: 3304-3313.

Kleen JK, Hooijer GA, Rehage J, Noordhuizen JP (2003) Subacute ruminal acidosis (SARA): a review. J Vet Med 50: 406-414.

Lohölter M, Rehage R, Meyer U, Lebzien P, Rehage J, Dänicke S (2013) Evaluation of a device for continuous measurement of rumen $\mathrm{pH}$ and temperature considering localization of measurement and dietary concentrate proportion. Appl Agric Forestry Res 63: 61-68. 
Nordlund KV, Garrett EF (1994) Rumenocentesis: a technique for collecting rumen fluid for the diagnosis of subacute rumen acidosis. Comp Cont Educ Pract Vet 17: $48-56$

Plaizier JC, Krausea DO, Gozho GN, McBride BW (2008) Subacute ruminal acidosis in dairy cows: the physiological causes, incidence and consequences. Vet J 176: 21-31.

Sievers AK, Kristensen NB, Laue HJ, Wolffram S (2004) Development of an intraruminal device for data sampling and transmission. J Anim Sci 13: 207-210.

Stone WC (2004) Nutritional approaches to minimize subacute ruminal acidosis and laminitis in dairy cattle. J Dairy Sci 87: 13-26.

Strabel D, Ewy A, Kaufmann T, Steiner A, Kirchhofer M (2007) Rumenozentese: eine geeignete Methode zur
$\mathrm{pH}$ Bestimmung im Pansensaft beim Rind? Schweiz. Arch. Tierheilkde 149: 301-306.

Svendsen P, Kristensen B (1970) Cecal dilatation in cattle. An experimental study of the etiology. Nord Vet Med 22: $578-583$.

Thompson P, Hentzen A, Schultheiss W (2006) The effect of rumen lesions in feedlot calves: which lesions really affect growth? Ruminant Day, University of Pretoria, Pretoria, South Africa, pp 23-27.

Wang Y, Majak W, McAllister TA (2012) Frothy bloat in ruminants: Cause, occurrence, and mitigation strategies Anim Feed Sci Technol 172: 103-114.

Westwood CT, Bramley E, Lean IJ (2003) Review of the relationship between nutrition and lameness in pasture-fed dairy cattle. N Z Vet J 51: 208-218. 